\title{
SEISMIC BEHAVIOUR OF POORLY DETAILED RC BRIDGE PIERS WITH HOLLOW CROSS-SECTION
}

\author{
Paolino Cassese ${ }^{1}$, Maria Teresa De Risi ${ }^{1}$, and Gerardo Mario Verderame ${ }^{1}$ \\ ${ }^{1}$ University of Naples Federico II \\ Department of Structures for Engineering and Architecture \\ via Claudio 21, 80125 Naples - Italy \\ paolino.cassese@unina.it,mariateresa.derisi@unina.it,verderam@unina.it
}

Keywords: Hollow rectangular cross-section, experimental tests, deformability contributions, numerical modelling.

\begin{abstract}
The assessment of seismic performance of existing bridge structures is a primary issue, especially in regions where most of bridges have been realized without proper details to support loadings due to earthquakes. Hollow section piers are a very common structural solution for reinforced concrete $(R C)$ bridge structures, due to the economical convenience and the higher structural efficiency with respect to solid sections. Nevertheless, a quite limited number of experimental tests are present in literature about this structural typology.

An experimental program of cyclic tests on four 1:4-scale models of typical RC existing bridge piers with hollow rectangular cross-section, poor structural detailing and small web thickness, has been carried out at the Department of Structures for Engineering and Architecture of the University of Naples Federico II. Different failure modes have been observed: flexure and flexure-shear, basically depending on the specimens' slenderness.

In this paper, major experimental results are described and discussed, also evaluating the deformability contributions to the overall applied displacement and highlighting the importance of shear deformation. Finally, numerical simulation analyses of the structural response of the tested piers have been performed in OpenSees in order to reproduce the above-mentioned deformability contributions by simulations. Main numerical-versus-experimental results are shown and discussed.
\end{abstract}




\section{INTRODUCTION}

The seismic vulnerability of existing highway bridges, and in particular of bridge piers designed according to obsolete technical codes, has been highlighted by several major earthquakes occurred throughout the world [1]. Various failure modes (FMs) of bridge columns have been identified during post-earthquake reconnaissance operations on transportation infrastructures. Generally, failure is related to a displacement-ductility capacity not adequate to the seismic demand, caused by not sufficient reinforcement details. In some cases, generally for columns with high aspect ratio (namely, columns height-to-section depth ratio), this lead to collapse for combined axial load and bending moment of the plastic regions located at the basis of the piers, with spalling and crushing of the compressed concrete, and longitudinal bars buckling In other cases, especially for medium-low aspect ratio columns, the premature collapse is due to a not sufficient not-degraded shear capacity ("shear" FM), or to the degradation of shear capacity caused by flexural damages during non-linear response ("flexureshear" FM).

If for Reinforced Concrete (RC) bridge columns with ordinary solid cross-section (in particular, rectangular and circular) the seismic assessment issue can be considered as quite comprehensive, since many experimental and analytical studies are available in literature (e.g. [24], among many others), this is not true for columns with hollow-core cross section, despite their widespread use transportation infrastructures. Only quite recently, attention has been paid to experimental cyclic response of hollow columns: relatively few experimental studies, especially if compared with columns with solid cross section, are available in literature. Some of the existing studies [5-8] highlighted that the lateral response of existing (poorly detailed) hollow RC piers is characterized by high shear deformations, comparable to ones typical of $\mathrm{RC}$ walls, which may represent also a considerable portion of global top displacement. Calvi et al. [5] observed that fiber models, good in capturing flexural response, needed corrections in order to include some stiffness reduction due to shear deformability. Delgado and his colleagues [6-8] noted that shear deformation of hollow piers cannot be captured with typical models, based on fiber or plastic hinge approaches; therefore, they adopted a more advanced numerical tools, with 3D finite elements and complex constitutive models, to adequately reproduce the experimental response of poorly detailed RC columns, both in terms of load and deformability.

This work aims at contributing to the investigation of the response under cyclic loading of $\mathrm{RC}$ existing bridge piers with hollow rectangular cross-section, characterized by medium-low aspect ratio and seismic reinforcement details non-conforming to modern seismic codes, therefore susceptible to high shear deformations and, eventually, shear failure. To this aim, in the present study, experimental cyclic tests on four RC piers with hollow rectangular crosssection typical of existing Italian bridges, are presented. Main global results and experimental deformability contributions due to flexure, shear, and fixed-end rotation, will be briefly described and analyzed. Then, the attention will be focused on the monotonic numerical modelling of the experimental force-displacement response, for all the tests. Primary goals of the numerical assessment are the adoption of simple and practice-oriented models available in literature [9-15] to adequately assess all the deformability contributions. The adopted threecomponent model will be briefly described, also analyzing partial results obtained for each component. Finally, the numerical results will be compared with the experimental ones, both at global and local level. 


\section{EXPERIMENTAL PROGRAM}

An experimental program of cyclic tests on four reduced-scale models of RC bridge columns with hollow rectangular cross-section has been carried out the Department of Structures for Engineering and Architecture of the University of Naples Federico II. Test specimens were designed to be representative of the existing bridge columns typical of the Italian transportation infrastructures realized before 1980. Starting from the results of a broad investigation on a sample of about 400 existing Italian bridges placed along main national roads [16], a typical bridge pier cross-section has been designed, as regards both geometry and reinforcement details, according with common non-seismic design practice. A scaling factor equal to 1:4 was introduced, for sake of convenience related to the capacity of the laboratory.

Schematic plan and elevation views of the hollow rectangular test specimens are illustrated in Figure 1. All the specimens are characterized by the same cross section and reinforcement details. Exterior dimensions of the rectangular hollow section are $600 \times 400 \mathrm{~mm}$ and thickness $\left(t_{w}\right)$ is $100 \mathrm{~mm}$. The longitudinal reinforcement ratio $\left(\rho^{\prime}\right)$ is equal to $0.88 \%$, given by 28 steel bars with a diameter $\left(\mathrm{d}_{\mathrm{b}}\right)$ equal to $8 \mathrm{~mm}$, arranged in two layers of 18 and 10 bars, along the external and internal edges respectively, with a concrete cover of $10 \mathrm{~mm}$. The transverse reinforcement ratio $\left(\rho^{\prime \prime}\right)$ is equal to $0.12 \%$, with stirrups of diameter $3 \mathrm{~mm}$, spaced at a distance of $120 \mathrm{~mm}$ and 90 -degree end hooks. The tested piers have different aspect ratio $(\mathrm{Lv} / \mathrm{H})$, in which Lv is the shear span (height from the base to the loading point) and $\mathrm{H}$ is the section depth (dimension of the cross-section in the loading direction). Two piers have a height of $900 \mathrm{~mm}$ and two of $1500 \mathrm{~mm}$. Each one has been tested along one of the two principal directions, so that four different values of the aspect ratio were considered, labelled as P1, P2, P3, and P4. Poor concrete has been reproduced, with a mean value of the compressive strength equal to 17.0 MPa. Steel with yielding stress of $540 \mathrm{MPa}$ and $650 \mathrm{MPa}$ has been used for longitudinal $\left(\mathrm{f}_{\mathrm{y}}\right)$ and transverse $\left(\mathrm{f}_{\mathrm{yw}}\right)$ reinforcement, respectively. Main geometric properties of specimens are summarized in Table 1 together with reinforcement details and material properties. Note that labels $\mathrm{B}$ and $\mathrm{H}$ in Table 1 represent the external dimensions of the cross-section, perpendicular and parallel to the imposed displacement direction, respectively.

\begin{tabular}{ccccccccccc}
\hline Test ID & $\begin{array}{c}\mathrm{L}_{\mathrm{V}} \\
(\mathrm{mm})\end{array}$ & $\begin{array}{c}\mathrm{B} \\
(\mathrm{mm})\end{array}$ & $\begin{array}{c}\mathrm{H} \\
(\mathrm{mm})\end{array}$ & $\begin{array}{c}\mathrm{L}_{\mathrm{V}} / \mathrm{H} \\
(-)\end{array}$ & $\begin{array}{c}\mathrm{t}_{\mathrm{w}} \\
(\mathrm{mm})\end{array}$ & $\begin{array}{c}\rho^{\prime} \\
(-)\end{array}$ & $\begin{array}{c}\rho^{\prime \prime} \\
(-)\end{array}$ & $\begin{array}{c}\mathrm{f}_{\mathrm{c}} \\
(\mathrm{MPa})\end{array}$ & $\begin{array}{c}\mathrm{f}_{\mathrm{y}} \\
(\mathrm{MPa})\end{array}$ & $\begin{array}{c}\mathrm{f}_{\mathrm{yw}} \\
(\mathrm{MPa})\end{array}$ \\
\hline P1 & 1500 & 400 & 600 & 2.50 & 100 & $0.88 \%$ & $0.12 \%$ & 17.0 & 540.0 & 650.0 \\
P2 & & 600 & 400 & 3.75 & & & & & & \\
P3 & 900 & 400 & 600 & 1.50 & & & & & & \\
P4 & & 600 & 400 & 2.25 & & & & & & \\
\hline
\end{tabular}

Table 1: Summary of geometrical, reinforcement details, and material properties.

On the top of each specimen, a solid cap was realized, in order to distribute axial and lateral loads on the hollow section avoiding eventual local damages. Footings were designed to prevent any local damage. All the tests were performed under quasi-static loading, by applying a constant compressive axial load, equal to $5 \%$ of the compressive axial capacity (within the typical serviceability axial load range of Italian bridges [16]). Axial load was applied by means of a closed system, composed of 3 post-tensioned high strength steel strands, fixed on the bottom side by means of anchorages embedded in the foundation, and tensioned through a hydraulic jack placed on the pier cap. Later, a cyclic displacement history was applied with increasing amplitude until failure occurred. The lateral displacement sequence consisted of three push/pull cycles at displacements equal to $1 / 3 \Delta_{y}, 2 / 3 \Delta_{y}, \Delta_{y}, 2 \Delta_{y}, 4 \Delta_{y}, 6 \Delta_{y}$, and so on, 
unless failure occurred earlier. The displacement at yielding $\left(\Delta_{\mathrm{y}}\right)$ was estimated according to [17].

In addition to the principal monitoring system, aiming measuring the global response (in terms of force and displacement), a secondary one was arranged in order to investigate deeply about local deformation mechanisms determining structural behavior of the columns (flexure, shear and bar slip at the column/foundation interface). A schematic view of both the global and local monitoring systems is reported in Figure 2.
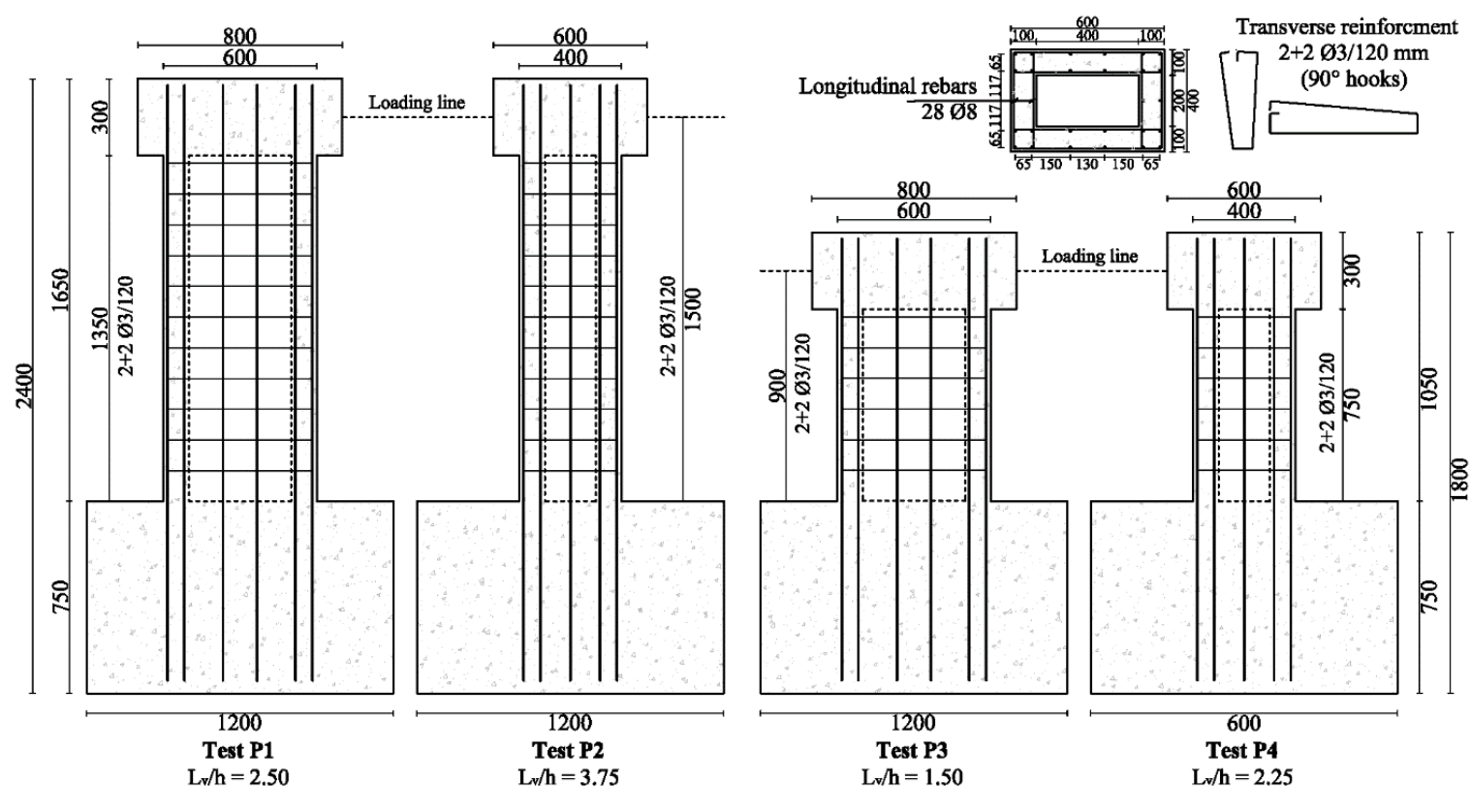

Figure 1: Geometry and reinforcement details.
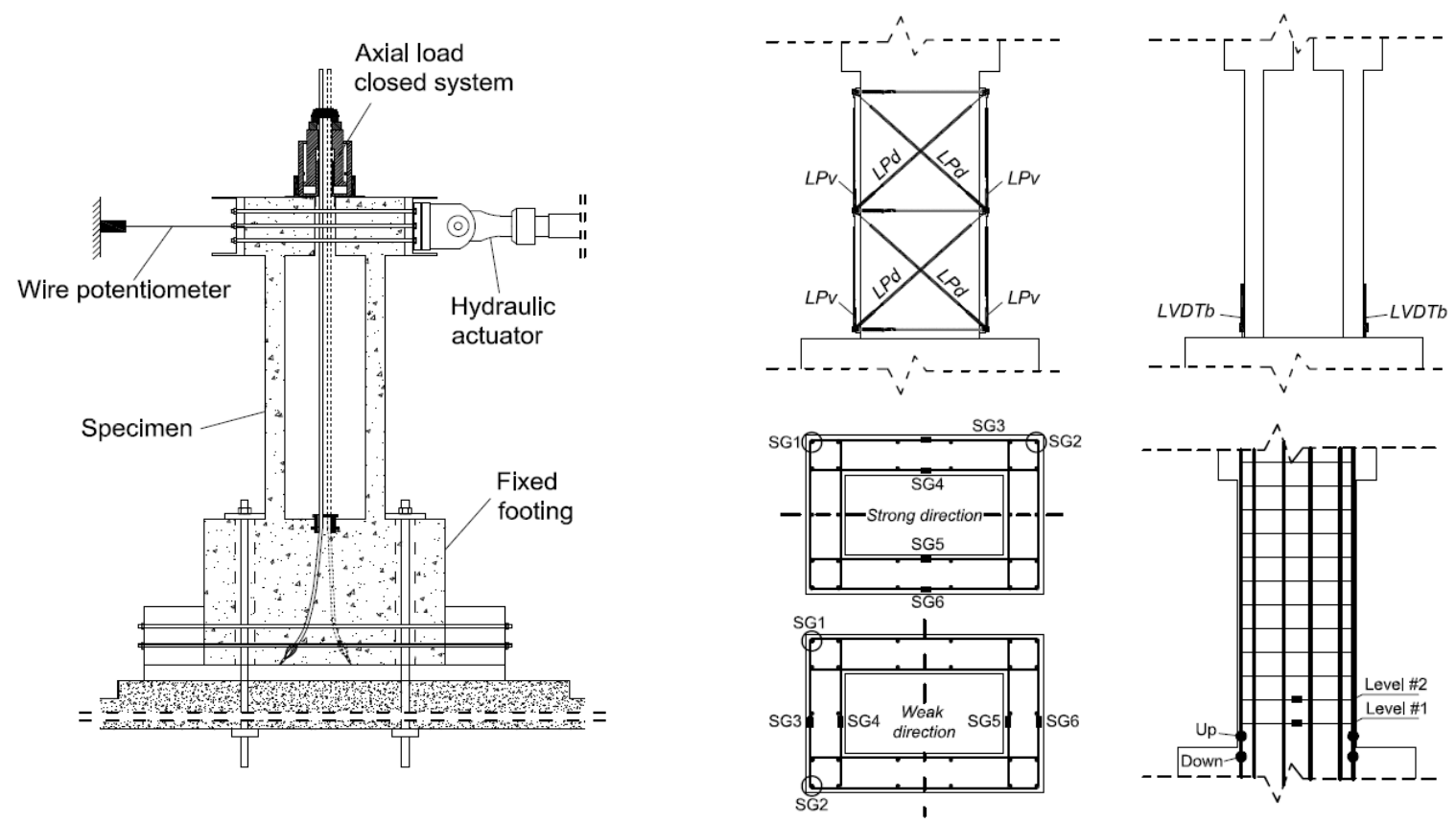

Figure 2: Schematic view of test setup and monitoring system 
The first system consisted of two load cells, for horizontal and vertical loads respectively, and a wire potentiometer located between an external fixed point and the centroid of the pier cap. The second monitoring system included: a frame of Linear Displacement Potentiometers (LDPs), located on the external surfaces parallel to the horizontal loading direction and defining two "monitoring panels" (Figure 2); a couple of vertical Linear Variable Displacement Transducers (LVDTs), fixed to the base of the test specimen on the surfaces orthogonal to lateral loading direction and connected to the foundation upper surface; a set of Strain Gauges (SGs), installed on some longitudinal and transverse reinforcement (as shown in Figure 2).

The LDPs were installed along vertical and diagonal directions, in order to monitor flexural and shear deformations along the specimen height. The LVDTs were mounted to measure the vertical deformations concentrated at the base of the column (due to flexure and bar slip). The SGs were attached to corner longitudinal bars and first two layers of transverse reinforcement to control steel longitudinal deformation during the tests.

\section{EXPERIMENTAL RESULTS}

In this section, the main experimental results are described and analyzed. In particular, first, the global response is discussed, based on registered hysteretic loops and observed damage states. Then, the attention is focused on the local behavior, by analyzing the experimental deformability contributions to the overall top displacement, due to flexure, shear and fixed-end rotation caused by longitudinal bars slip at column/foundation interface.

\subsection{Global response}

Test $\mathrm{P} 1$, characterized by an aspect ratio equal to 2.50 , was subjected to flexural failure. The results in terms of lateral load versus drift response are shown in Figure 3(a). Experimental response appears quite symmetric during the push-pull cycles. During the first cycle $(\mathrm{drift}=0.08 \%)$, for a force equal to about $50 \mathrm{kN}$, first flexural cracks appeared, causing a reduction of the initial stiffness. For a drift range between $0.08 \%$ and $0.34 \%$, the existing flexural cracks evolved along diagonal directions. First shear crack appeared in the central part at about $90 \mathrm{kN}$ lateral load, with a subsequent stiffness decrease. Strain gauge registered yielding condition at force of $+132 \mathrm{kN} /-116 \mathrm{kN}$, in push and pull direction, respectively. Peak load values were equal to $+168 \mathrm{kN} /-164 \mathrm{kN}$. Damage state was characterized by extension and increasing in width of existing cracks and longitudinal bars buckling at the base of the column. The post-peak response was governed by flexure, with a gradual degradation due to concrete spalling, buckling of longitudinal bars within the distance between the base and the first layer of transverse reinforcement, and widening of the existing diagonal cracks. During the last cycle $($ drift $=4.37 \%)$, concrete of the compressed flanges was completely crashed and spalled. Longitudinal corner bars failed in tension due to oligo-cyclic fatigue caused by buckling/tension cycles. This caused a sudden intra-cycle strength drop/stiffness decrease equal to $-52 \% /-43 \%$ of the peak load, in push and pull directions respectively.

Test P2, characterized by an aspect ratio equal to 3.75, failed in a flexural failure mode. The results in terms of lateral load versus drift response are shown in Figure 3(b). The experimental response appeared quite symmetric during the push-pull cycles only up to peak load. A first reduction of the initial stiffness was observed for a lateral load value of about $45 \mathrm{kN}$, for which hairline flexural cracks were observed. For a drift range between $0.23 \%$ and $0.79 \%$, the existing flexural cracks evolved along diagonal directions, causing gradual stiffness decrease. Specimen reached first yielding condition at lateral load of $+89 \mathrm{kN} /-87 \mathrm{kN}$. Peak load of $+117 \mathrm{kN} /-115 \mathrm{kN}$ was reached for a drift equal to $3.50 \%$. Diagonal cracks increased their width suddenly, intersecting with each other in correspondence of the central longitudinal bar, 
causing concrete cover spalling along a vertical centerline. Damage at the base of the column developed quickly: vertical cracks appeared on cover corners due to longitudinal bars buckling. The post-peak response was asymmetric and governed by flexure. The asymmetry of the response was essentially due to the failure in tension (because of oligo-cyclic fatigue) of corner longitudinal bars. This phenomenon implicated a severe intra-cycle strength drop/stiffness decrease in negative/positive direction ( $45 \%$ in push direction and $60 \%$ in pull with respect to the peak lateral load).

Test P3, characterized by an aspect ratio equal to 1.50 , failed in shear after flexural yielding. The results in terms of lateral load versus drift response are shown in Figure 3(c). Experimental response appeared slightly non-symmetric during the push-pull cycles. This effect, more evident with increasing drift, is associated with the shear cracking extension and reversal process. A first reduction of the initial stiffness was observed for lateral load of $+69 \mathrm{kN} /-$ $58 \mathrm{~N}$, corresponding to the opening of slight cracks at the base/foundation interface. For a drift range between $0.02 \%$ and $0.28 \%$, flexural cracks formed, quickly evolving along diagonal directions towards compressed zone. Two diagonal cracks formed from top to down opposite corners at $+195 \mathrm{kN} /-161 \mathrm{kN}$, with an inclination angle of about 45 degrees. Longitudinal bars reached yielding strain value at $+256 \mathrm{kN} /-211 \mathrm{kN}$ lateral load. Damage state developed quickly: existing shear cracks increased their width and length, particularly two principal ones. Unlike Test P1 and Test P2, no considerable damage was observed on the base zone. Last loading step was characterized by a single complete push/pull cycle. During pushing phase, for a drift value of $+1.26 \%$, the main existing shear crack opened suddenly. This caused a severe drop in strength, equal to $58 \%$ of the peak load. Following pull phase was characterized by a lower stiffness. For a drift equal to $-1.16 \%$ another drop in strength was observed, corresponding to the opening of a reverse diagonal crack.

Test P4, characterized by an aspect ratio equal to 2.25, failed in shear after flexural yielding. The results in terms of lateral load versus drift response are shown in Figure 3(d). Experimental response appeared quite symmetric during all the applied push-pull cycles. A first reduction of the initial stiffness was observed for lateral load of $57 \mathrm{kN}$, corresponding to first slight cracks at the base/foundation interface. Stiffness decreased gradually during second and third cycles, for a drift range between $0.06 \%$ and $0.43 \%$. Two diagonal cracks formed from top to down opposite corners with an inclination angle of about 38 degrees, at lateral load of $132 \mathrm{kN}$. Specimen reached yielding condition at $+152 \mathrm{kN} /-149 \mathrm{kN}$ load, and existing shear cracks increased their width. When peak load of $+193 \mathrm{kN} /-188 \mathrm{kN}$, main diagonal cracks widened and extended up to base corners, causing concrete cover cracking and longitudinal bars buckling. Last loading step was characterized by one push/pull cycle. During pushing phase, for a drift value of $+2.80 \%$, a sudden opening of main diagonal crack was observed. During the following pull phase, for a drift value of $-2.49 \%$, a reverse diagonal crack opened. A clear sliding between the upper and the lower part of the specimen appeared, with buckling of longitudinal bars crossing the shear crack, and at the base, with resulting concrete cover spalling. A sudden strength drop, equal to $54 \%$ of the global peak load, was observed.

Final damage states are reported in Figure 4 for all the tests. By observing Figure 4, it is interesting to note the substantial difference of the overall damage state between the taller specimens (namely, tests P1 and P2) and the shorter specimens (namely, tests P3 and P4), as expected. However, a considerable flexure-shear interaction exists for all the tests, resulting in a complex and diffused crack pattern, with diagonal cracks due to shear. Such a phenomenological interaction has been confirmed by the local measures (see section 3.2). 


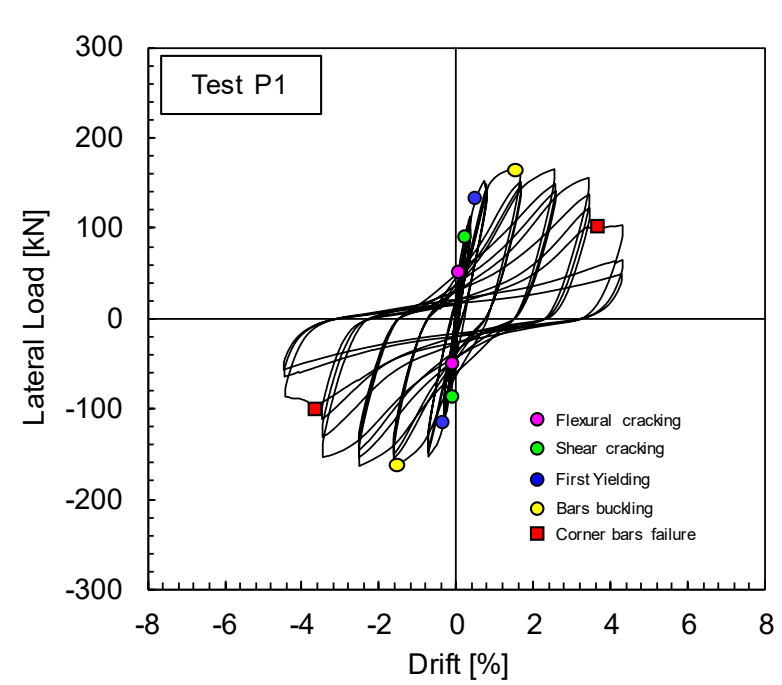

(a)

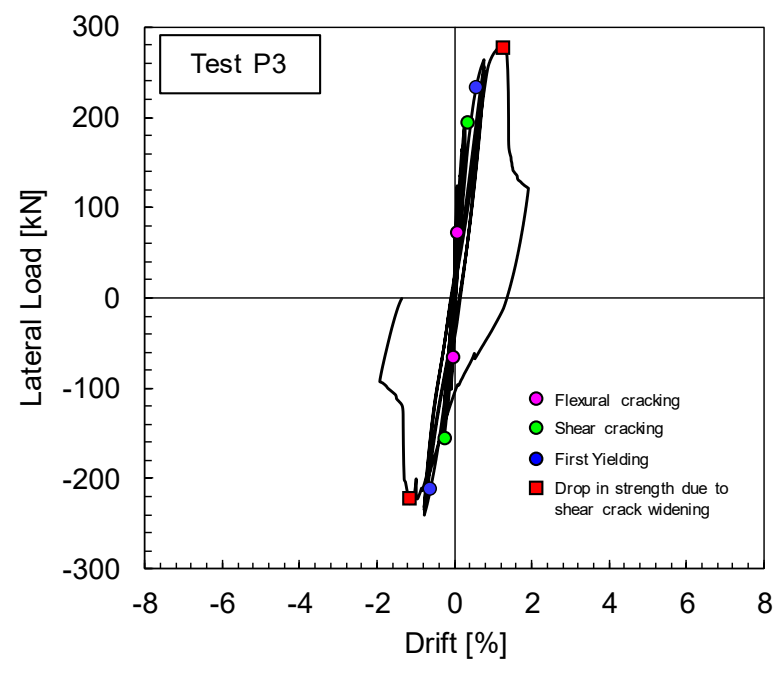

(c)

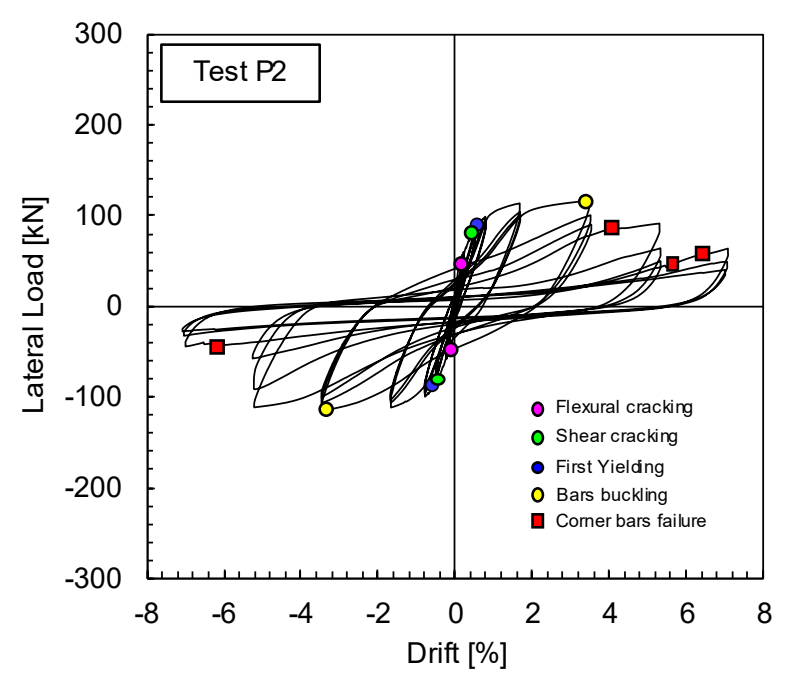

(b)

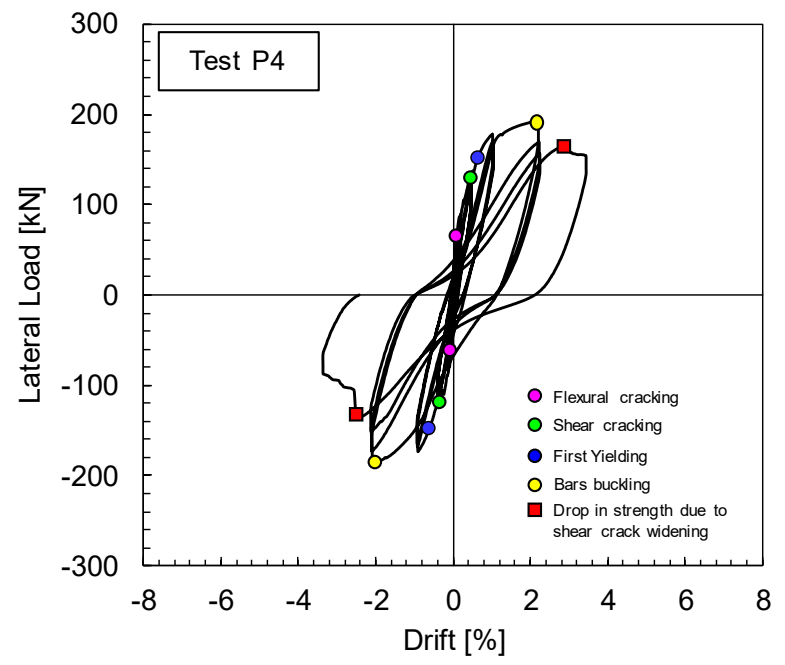

(d)

Figure 3: Experimental response in terms of lateral load vs drift for tests P1 (a), P2 (b), P3 (c), and P4 (d).

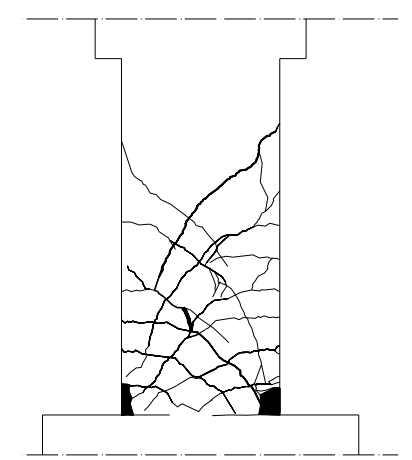

(a)

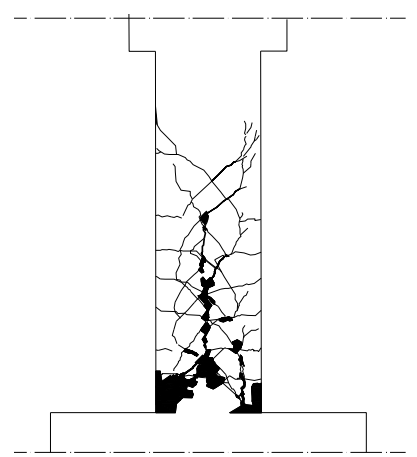

(b)

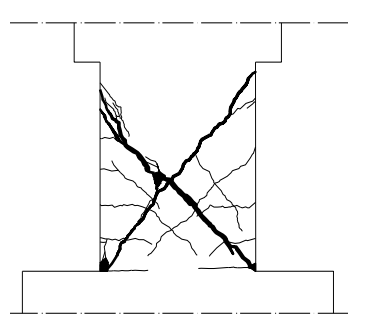

(c)

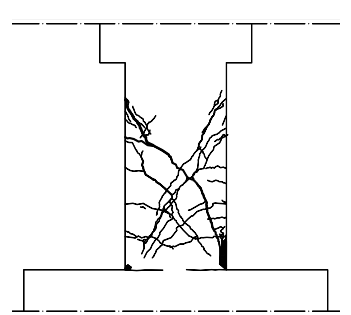

(d)

Figure 4: Final damage state for tests P1 (a), P2 (b), P3 (c), and P4 (d). 


\subsection{Local behavior}

The top displacement of the specimen $(\Delta)$ can be interpreted as the result of three deformation mechanisms: flexure $\left(\Delta_{\mathrm{f}}\right)$, shear deformation along webs $\left(\Delta_{\mathrm{s}}\right)$ and fixed-end-rotation due to longitudinal bar slip at column base $\left(\Delta_{\theta}\right)$ (see Figure 5).
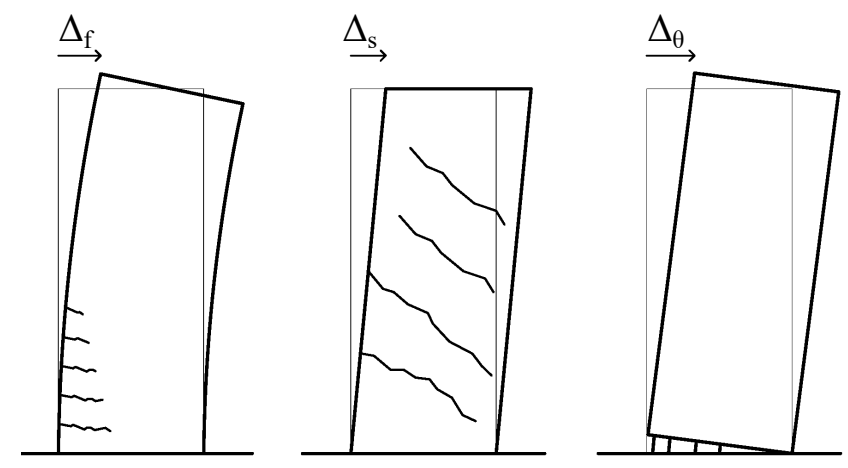

Figure 5: Deformability contributions to total displacement.

By assuming a uniform curvature distribution along each "monitoring panel", the flexural component $\Delta_{\mathrm{f}}$ can be calculated as the sum of the rotations measured by the vertical LDPs multiplied by corresponding distances from the top of the column.

The fixed-end-rotation contribution $\Delta_{\theta}$ is due to the slippage from the foundation and it cannot be directly evaluated; instead, the base rotation $\theta_{\mathrm{b}}$ can be measured by the two LVDTs monitoring vertical deformation along a height of $50 \mathrm{~mm}$ from the base section. $\theta_{\mathrm{b}}$ is associated to the base crack width, including bars slip at column/foundation interface, and to flexural deformation at the base zone. The corresponding displacement $\Delta_{\mathrm{b}}$ was calculated by multiplying the base rotation and the corresponding distance from the top of the column.

Finally, the shear component $\Delta_{\mathrm{s}}$ was estimated based on the hypothesis of small angles and uniform shear deformation over each measuring panel height. It is noteworthy to underline that the subdivision of deformations of inelastic RC hollow piers into shear and flexural deformations can provide a useful link between the experiments and numerical models, particularly if beam models are used. The assessment of the shear contribution to lateral displacement in the inelastic range is particularly interesting, to better understand whether shear deformations are essential to consider in structural analysis.

Figure 6 shows the ratio between measured deformability contributions and total displacement, corresponding to shear cracking, yielding and peak load conditions, for all the specimens. Note that in Figure 6 the contributions due to the base rotation $\left(\Delta_{b}\right)$ and flexure $\left(\Delta_{\mathrm{f}}\right)$ are summed up, since they represent a unique "flexural term", as explained above.

For all the tests, flexural deformability contribution was predominant with respect to the shear one. As expected, a relation between shear contribution to top displacement $\left(\Delta_{\mathrm{S}} / \Delta\right)$ and aspect ratio $(\mathrm{Lv} / \mathrm{H})$ can be observed. Shear contribution increases if aspect ratio decreases. In fact, for the slenderest specimen (i.e. test P2) the maximum value of the shear contribution is equal to $10.8 \%$. For specimens $\mathrm{P} 1$ and $\mathrm{P} 4$, characterized by similar aspect ratios (equal to 2.50 and 2.25 respectively), maximum shear contribution is about $20.0 \%$ of the top displacement. Finally, for the squat specimen (test P3), the maximum value of $\Delta_{\mathrm{s}} / \Delta$ is equal to $44.9 \%$. Furthermore, shear contribution is characterized by a clear increasing trend with the drift demand for specimens P1, P3, and P4 (with aspect ratios less than 3), and by an almost constant trend for specimen $\mathrm{P} 2$. 


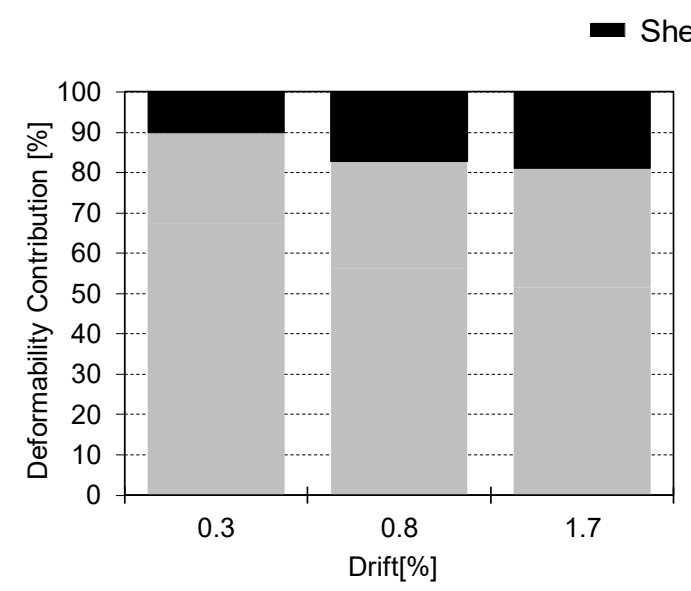

(a)

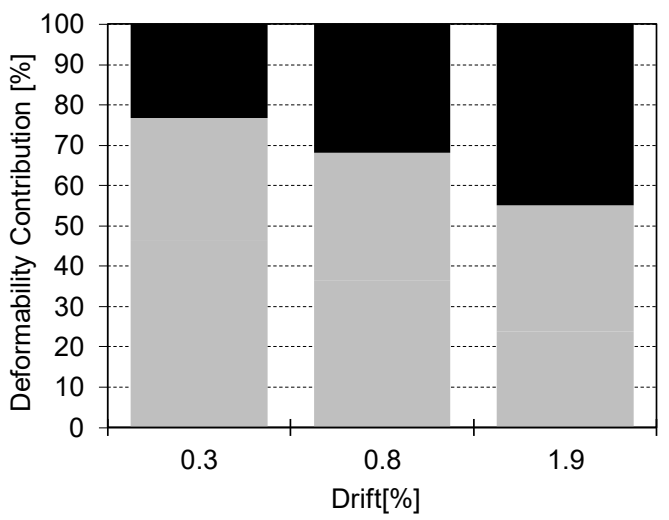

(c)

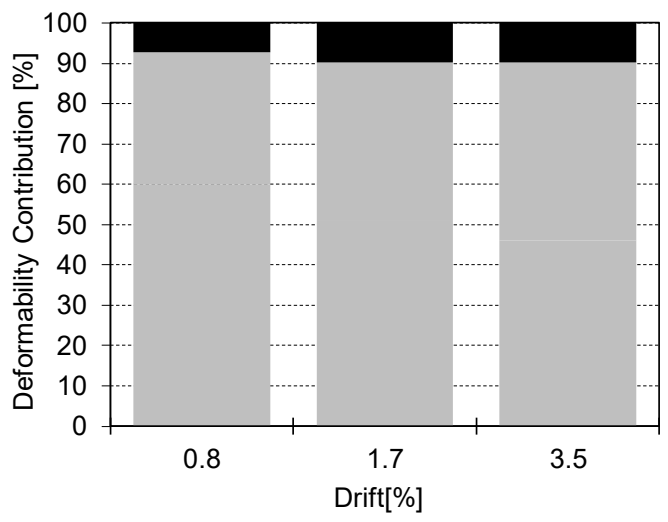

(b)

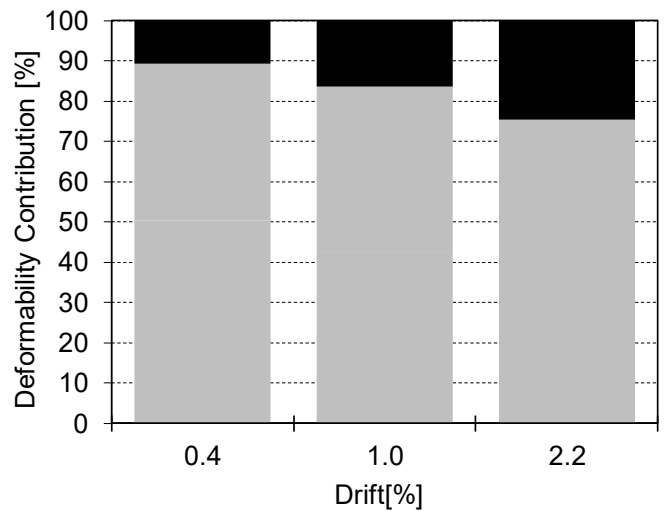

(d)

Figure 6: Experimental deformability contribution to top displacement corresponding to shear cracking, yielding and peak load conditions (first, second and third bar, respectively), for tests P1 (a), P2 (b), P3 (c), and P4 (d).

\section{NUMERICAL MODELLING}

Several models are available in literature to simulate the actual behavior of structures. Generally, the response of RC columns subjected to lateral load can be interpreted as the results of three coexisting mechanisms: flexure deformation, shear deformation, and fixed-endrotation due to longitudinal bar slip at column base. While for columns with height-to-depth ratio higher than 3 the shear flexibility can be neglected [14], the latter has to be considered for columns characterized by medium-low aspect ratios. This is confirmed also by the experimental measures presented in the previous section, which highlight non-negligible shear deformations for all the tests.

In this section, a load-deformation numerical model is carried out to reproduce the experimental responses of the tests $\mathrm{P} 1, \mathrm{P} 2, \mathrm{P} 3$, and $\mathrm{P} 4$. The main goal is the monotonic modelling of the experimental tests, and, in particular, the assessment of the experimental local deformability contributions. To this aim, a three-component model is adopted, in which the three mechanisms characterizing the lateral response of RC columns are separately modelled (see Figure 7). In the following, first, the adopted numerical model is briefly described and analyzed. Then, numerical results are compared to the corresponding experimental measures, both for global and local responses. 


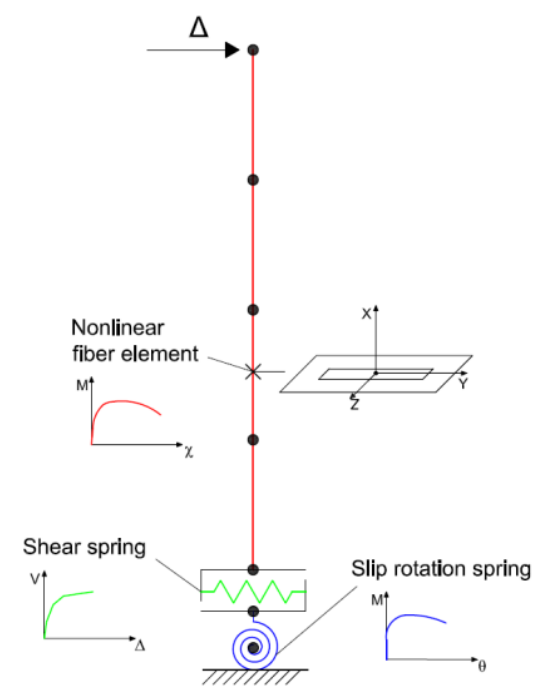

Figure 7: Scheme of the adopted three-component numerical model.

\subsection{Flexural component}

Flexural response is modelled with a displacement-based nonlinear beam-column fiber element in a distributed plasticity approach, available in OpenSees software [18], with five Gauss-Lobatto integration points. The cross section has been divided into 6400 concrete fibers. In addition, 28 steel fibers have been used to model the longitudinal reinforcement. The cross-section discretization is depicted in Figure 8. Two different stress-strain relationships have been used to describe the mechanical behavior of concrete and steel, and then assigned to the corresponding fibers of the column model. Since the specimens were characterized by the absence of reinforcement details (no tie between opposite longitudinal bars, $90^{\circ}$ hooks, high spacing between stirrups), unconfined concrete is assumed for all concrete fibers. The mechanical behavior of unconfined concrete has been modelled with the law by Popovics [9]. The constitutive model by Giuffré-Menegotto-Pinto [10] has been adopted for steel. These material models have been calibrated on the experimental results of the characterization tests carried out on the specimens collected during the construction stage.

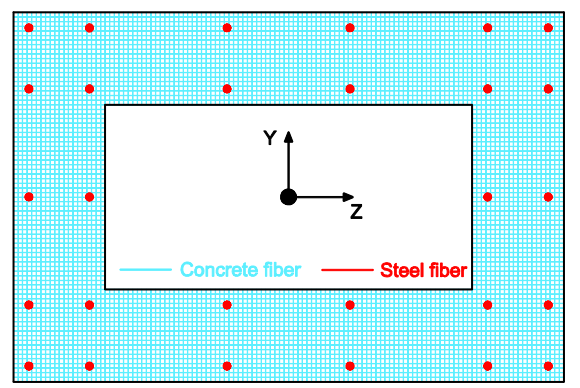

Figure 8: Fiber discretization of the transverse cross-section.

In Figure 9, the resulting moment-curvature relationships are reported for all the specimens, with the comparisons between experimental and predicted values of cracking, yielding and peak moment. The experimental yielding moments are well predicted by the fiber section analysis, with a slight overestimation for tests P2 and P4. Slightly less good are the predictions of the flexural cracking moment, with a mean error, evaluated as the predicted-to- 
experimental cracking moment ratio, equal to $15 \%$. The peak loads are well predicted for tests P1 and P2, subjected to flexural failure. For tests P3 and P4, the experimental peak values are lower than the predicted ones, since shear failure occurred before flexural capacity was reached.
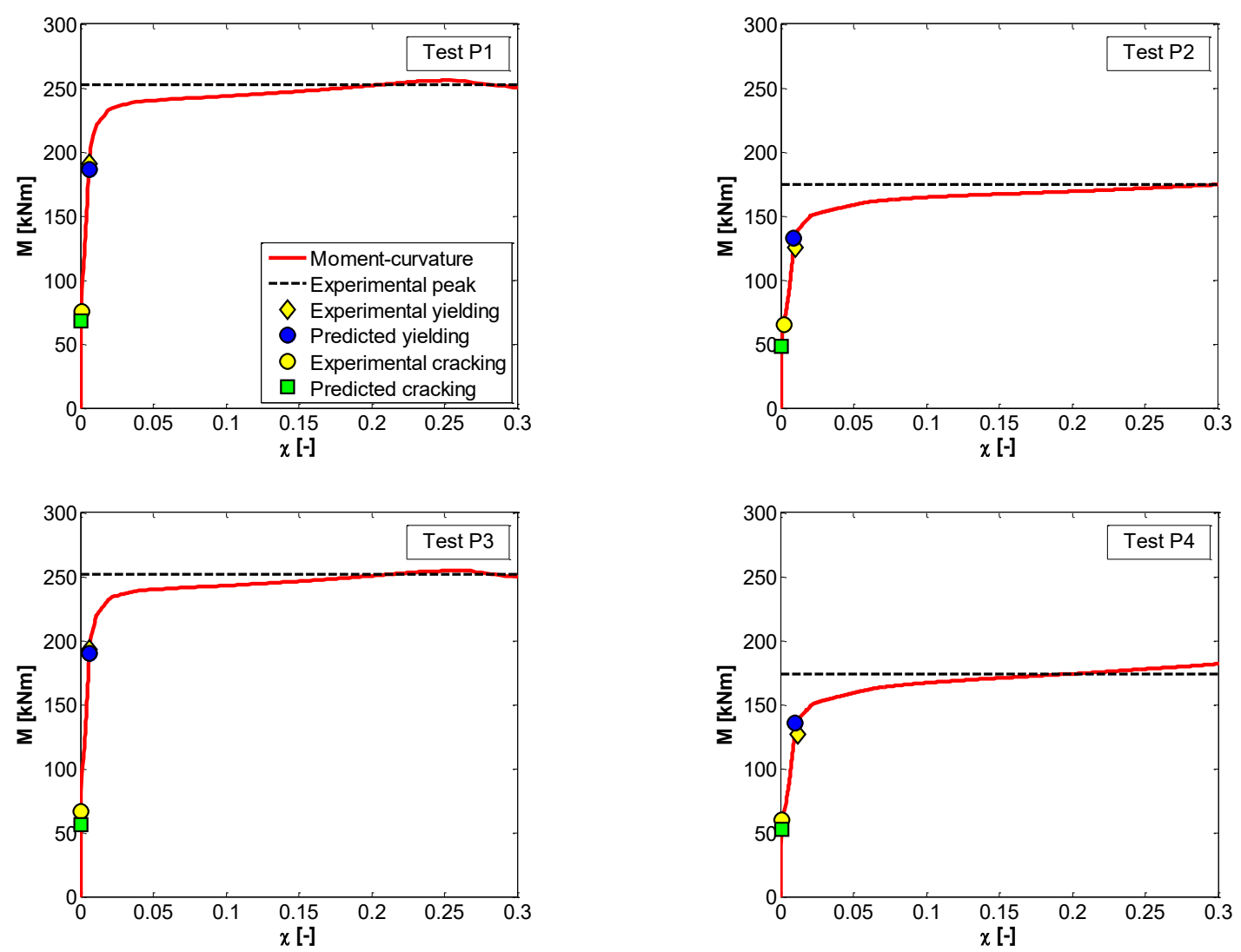

Figure 9: Moment-curvature predictions compared with experimental results

\subsection{Shear component}

The shear flexibility of the test specimens up to the peak force is accounted through the procedure proposed by Krolicki et al. [11]. This procedure was initially presented by Park and Paulay [12], later improved by Miranda et al. [13], and updated by Priestley et al. [14]. Finally, it was revised by Krolicki et al. [11], which applied the procedure to obtain the lateral response of reinforced concrete walls. According to this approach, the calculation of shear deformation is carried out assuming a multilinear response. Starting from the fiber momentcurvature $(\mathrm{M}, \chi)$ relationship for the base critical section, four phases are identified, each one characterized by a different shear stiffness.

The first phase characterizes the shear response prior to flexural cracking ( $\left.M \leq \mathrm{M}_{\mathrm{f}, \mathrm{cr}}\right)$. Shear stiffness of uncracked column is assumed as that given by Park and Paulay [12], depending on the shear elastic modulus $(G)$, and the effective shear area $\left(A_{v}\right)$, assumed as the product of thickness $\left(t_{\mathrm{w}}\right)$ and effective depth of the cross section $(\mathrm{d})$ - the latter defined as 0.8 times the cross-sectional height $(\mathrm{H})$.

The second phase defines the shear response between flexural cracking and diagonal cracking $\left(\mathrm{M}_{\mathrm{f}, \mathrm{cr}} \leq \mathrm{M} \leq \mathrm{M}_{\mathrm{s}, \mathrm{cr}}\right)$. Shear stiffness prior to shear cracking is approximately proportional to 
the reduction in flexural stiffness, assumed as the ratio between inertia moments of the uncracked and cracked section.

The third phase characterizes the shear response between shear cracking and yielding $\left(\mathrm{M}_{\mathrm{s}, \mathrm{cr}} \leq \mathrm{M} \leq \mathrm{M}_{\mathrm{y}}\right)$. Shear stiffness after the onset of diagonal cracking is based on an equivalent strut-and-tie model, incorporating both the compression of the diagonal strut, and the extension of the tie representing the transverse reinforcement. Such a stiffness depends on the transverse reinforcement ratio $\left(\rho^{\prime \prime}\right)$, the angle between diagonal cracks and member axis $(\theta)$, the steel Young's modulus $\left(E_{s}\right)$, and the effective depth $(d)$.

In the post-yield phase $\left(\mathrm{M}_{\mathrm{y}} \leq \mathrm{M} \leq \mathrm{M}_{\max }\right)$, the concrete compression struts will continue to soften, and thus shear deformation will continue to increase. Therefore, after first flexural yielding, the shear deformation increases proportional to the flexural deformation through the ratio between the top flexural lateral displacement corresponding to first yielding moment $\left(\Delta_{\mathrm{f}, \mathrm{y}}\right)$ and the top shear displacement corresponding to first yielding moment $\left(\Delta_{\mathrm{s}, \mathrm{sc}}\right)$.

In Figure 10, the predicted relationships between lateral-load (V) and shear-displacement (expressed in terms of drift ratio) are reported for all the specimens, together with the characteristic points of the lateral response, namely, numerical flexural cracking, flexural yielding and peak load, and experimental shear cracking. Note that experimental values of $\theta$ and $\mathrm{M}_{\mathrm{s}, \mathrm{cr}}$ are adopted herein. The predicted response is assessed starting from the momentcurvature analysis: for each of the four above-described phases, the corresponding moment values are used to compute the related displacement due to shear deformability.
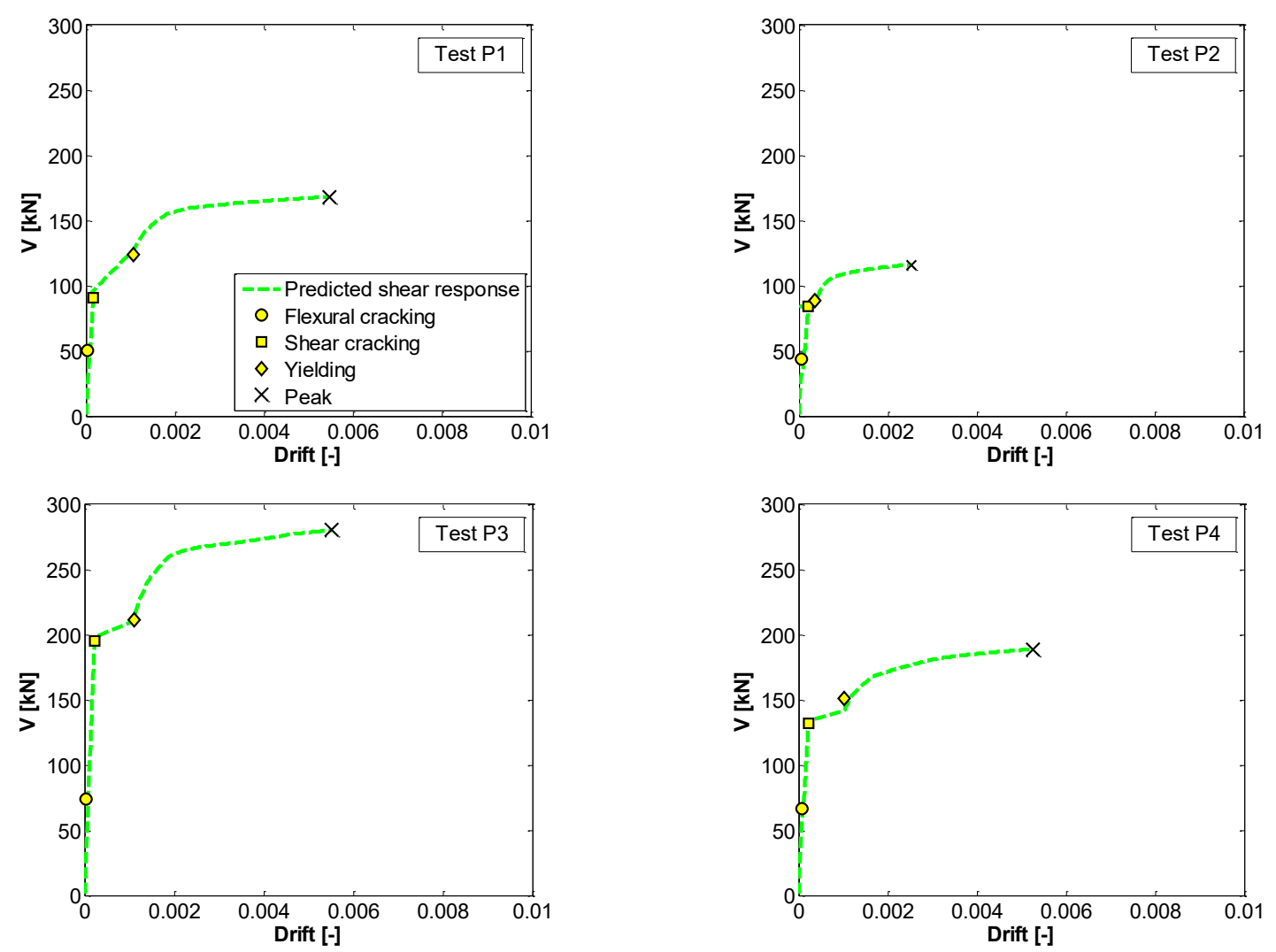

Figure 10: Predicted lateral load-shear displacement response

As expected, the shear deformability at peak load condition is very low for the slenderest specimen P2, while it is almost similar for the remaining specimens. For all the specimens, the shear stiffness is very high up to the onset of diagonal cracks, showing an almost rigid be- 
havior up to the first flexural yielding. After first diagonal cracking, shear deformation increases with the drift demand as a function of the measured inclination of the compressive strut, since all the other parameters defining the model are constant for all the specimens. Note that the values of lateral load corresponding to first shear cracking and yielding are very similar for test P2. For this reason, the increase of shear deformation in this phase is almost negligible. Once yielding condition is reached, shear deformation increase proportionally to flexural deformations.

\subsection{Bar slip component}

Slip of the reinforcing bars outside the flexure length and in the footing region will cause rigid-body rotation of the column, additive to the rotation due to flexure. Sometimes, reinforcement slippage in footings regions can lead to a significant contribution to the total lateral displacement of a reinforced concrete member; therefore, deformations resulting from reinforcement slip have to be accounted in the member analysis.

Several bar slip models are available in literature for deformed bars. In this study, a practice-oriented model proposed by Sezen and Setzler [15] is adopted. This model assumes a stepped function for bond stress between the concrete and reinforcing steel over the embedment length of the bar within the foundation. The column lateral displacement due to reinforcement slip is finally equal to the product between the slip rotation and the column length.
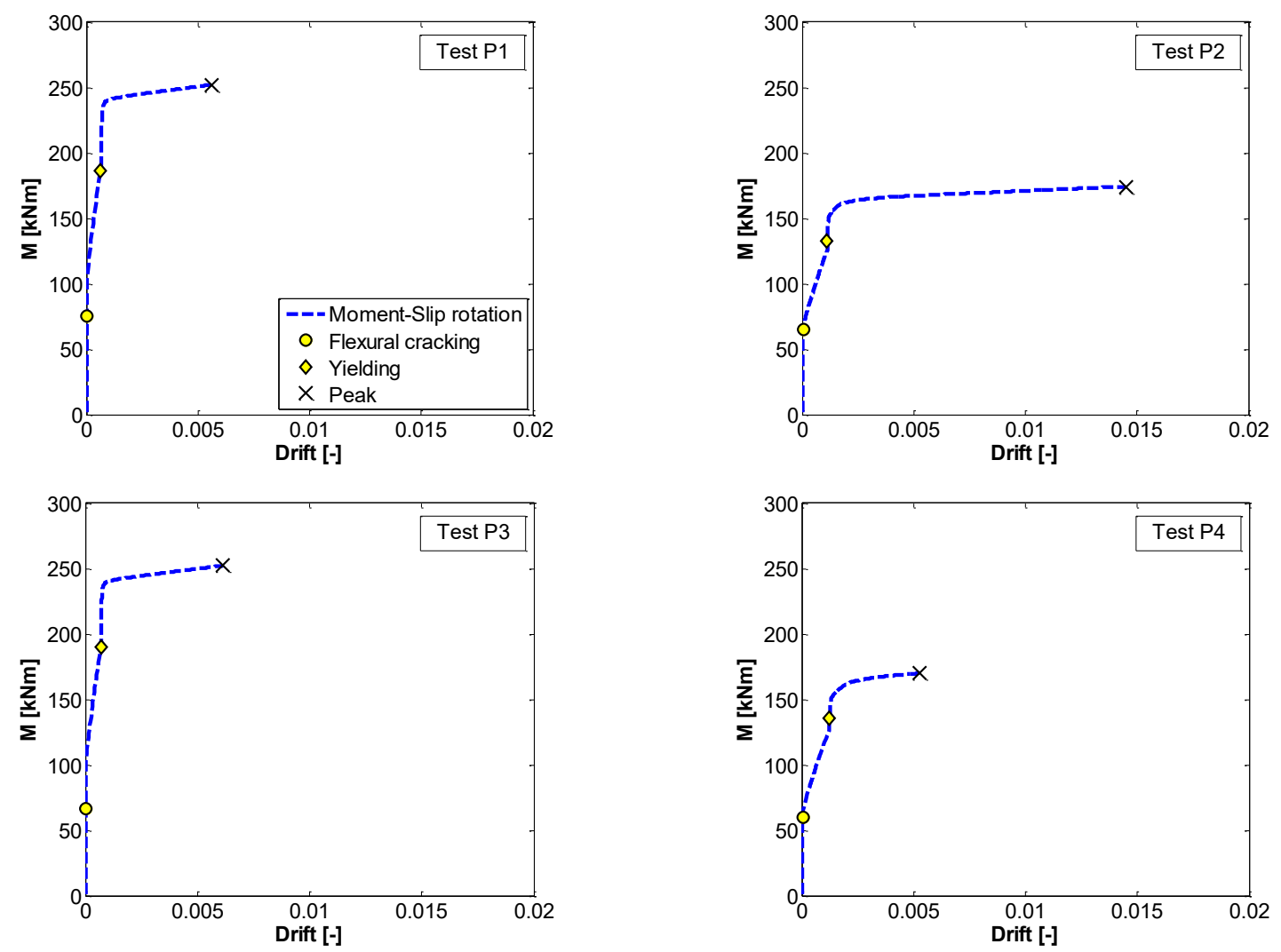

Figure.11. Predicted moment-slip rotation response

In Figure 11, the predicted relationships between moment and slip-rotation are reported for all the specimens, together with the numerical flexural cracking and yielding points. Also in this case, the predicted response is assessed starting from the moment-curvature analysis: for each value of moment, the corresponding bar stress and the related slip-rotation are computed. 
The rotation due to reinforcement slip is higher for specimen $\mathrm{P} 2$, characterized by the higher value of aspect-ratio and whose response was dominated by flexural mechanisms. The deformation due to slip at peak load condition is almost comparable among the remaining specimens.

\subsection{Comparison with experimental results}

The experimental deformability contributions can be assumed as reliable up to the peak load, due to the severe damage state characterizing the test specimens, which compromised the monitoring system. Since, as above discussed, the main goal of the numerical analysis is to reproduce the experimental deformability contributions, the numerical lateral response is particularly investigated up to the peak load condition, through the numerical model defined in the previous sections.

In Figure 12, the monotonic numerical global response (red line) is compared with cyclic experimental loops for all the specimens.
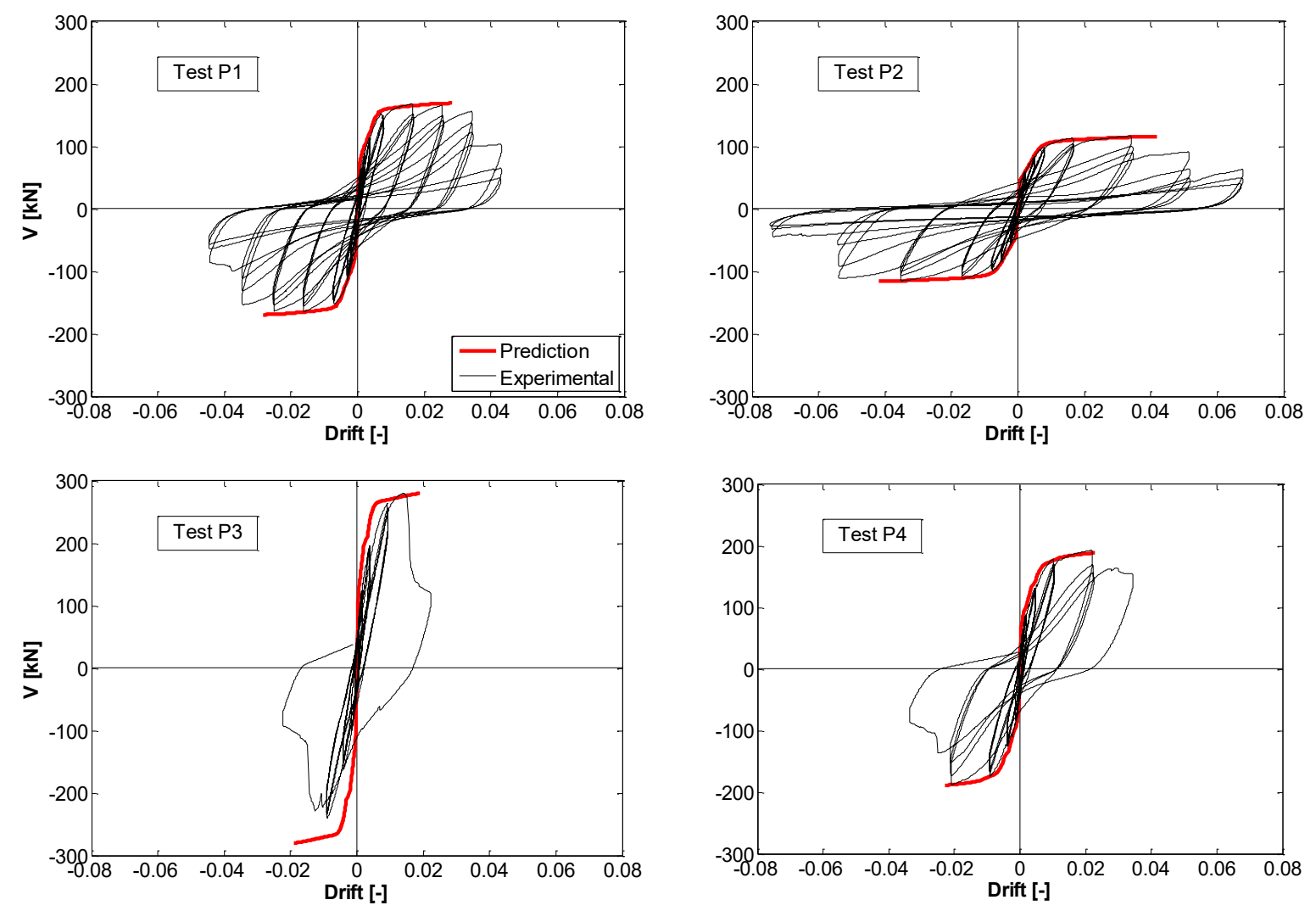

Figure 12: Predicted global response and flexure, shear and bar slip components

The monotonic numerical model is able to well reproduce the envelope of the experimental global response up to peak condition for all the specimens. For tests P3 and P4, subjected to flexure-shear failure, the numerical model slightly overestimates the negative peak load (namely, measured during pull phase). This is due to the experimental asymmetry caused by the shear damage state: once the peak load is reached during pushing phase, diagonal cracks caused a degradation of strength in the reverse (pull) direction.

It is very interesting to compare the experimental deformability contributions with those numerically obtained, reported in section 3.2. The numerical deformability contributions are shown in Figure 13 for the characteristic points of the experimental response: first shear 
cracking, yielding and peak load. The experimental mean trends of the deformability contributions to the overall imposed drift are well reproduced by the numerical model for all the specimens. In particular, the almost constant trend of the shear contribution for the specimen P2 is captured by the numerical analysis. Similarly, the increasing trend of the shear contribution with the drift demand is well represented for all the other specimens.

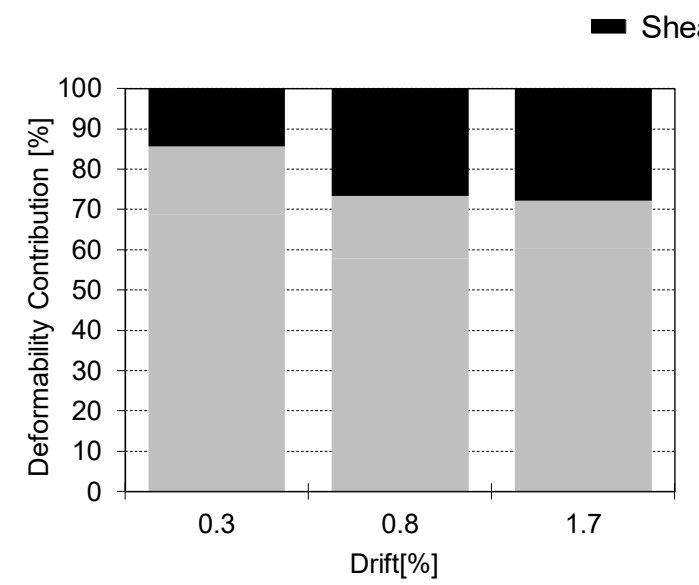

(a)

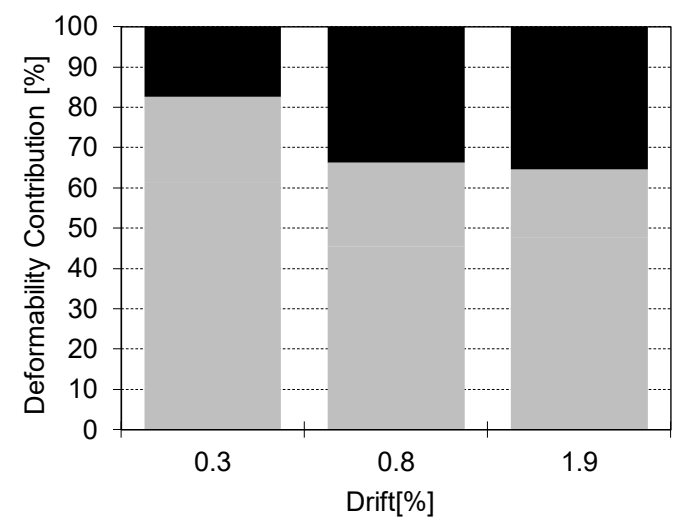

(c)

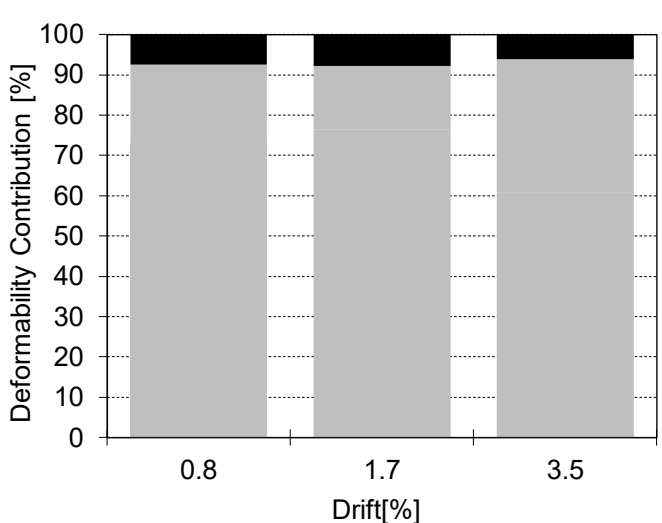

(b)

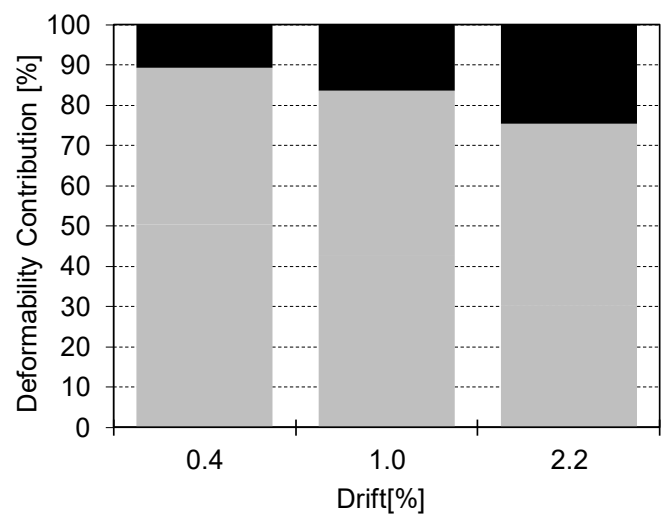

(d)

Figure 13: Numerical deformability contribution to top displacement corresponding to shear cracking, yielding and peak load conditions (first, second and third bar, respectively), for tests P1 (a), P2 (b), P3 (c), and P4 (d)

An explicit comparison between experimental and numerical deformability contributions is depicted in Figure 14. In particular, the numerical deformability contributions are evaluated for the experimental values of displacement corresponding to shear cracking, yielding and peak load. The numerical flexural contribution accounts for both flexure and fixed-end rotation, in order to be directly compared with the corresponding experimental value. On the horizontal and vertical axis are reported the experimental and numerical flexural contributions, respectively. The plots of Figure 14 confirm the very good agreement between experimental and numerical values: all the points are close to the bisector, highlighting an almost exact reproduction of the experimental deformability contributions.

\section{CONCLUSIONS AND FUTURE DEVELOPMENTS}

A quite limited number of experimental tests exist in literature about hollow section piers non-conforming to more updated seismic codes, a very common structural typology for Reinforced Concrete $(\mathrm{RC})$ bridge structures. Therefore, this work aims at contributing to the inves- 
tigation of the response under cyclic loading of this typology of RC existing bridge piers. A proper experimental program of cyclic tests on four scale models of typical RC existing bridge characterized by medium-low aspect ratio and seismic reinforcement details nonconforming to modern seismic codes was carried out, and analyzed and modeled in this paper.

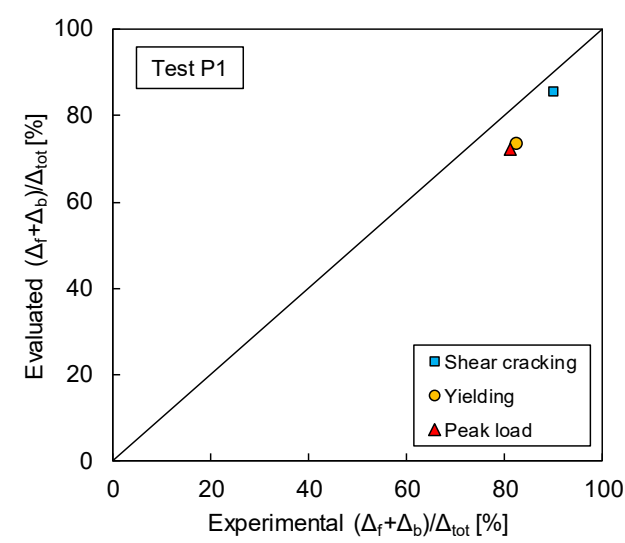

(a)

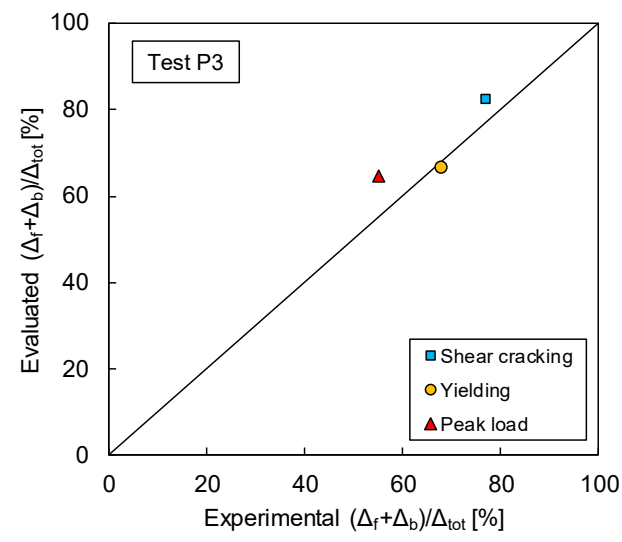

(c)

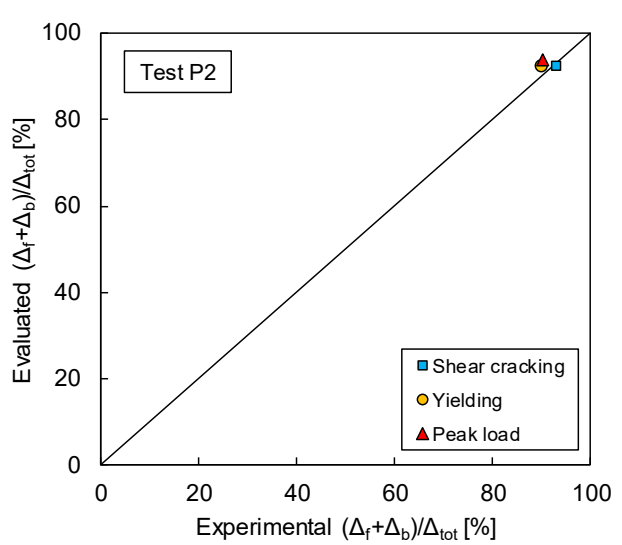

(b)

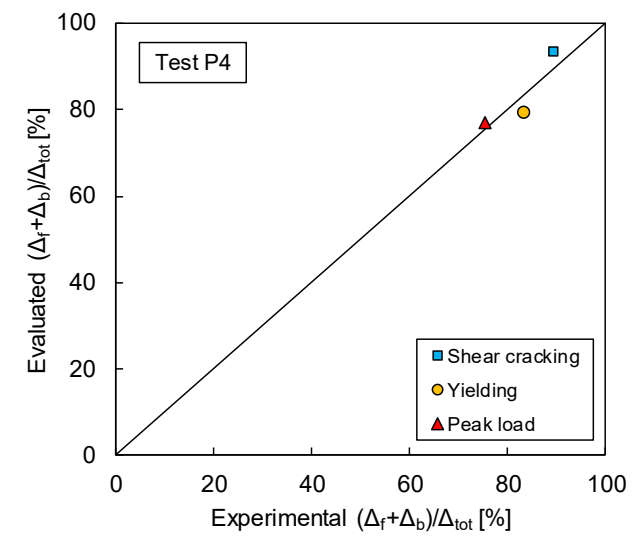

(d)

Figure 14: Comparison between averaged experimental (a) and numerical (b) flexural deformability contribution for Tests P1 (a), P2 (b), P3 (c), and P4 (d)

Basically, two different failure modes were observed, flexure and flexure-shear, depending on the specimens slenderness. Final damage states highlighted a considerable flexure-shear interaction for all the tests, resulting in a complex and diffused crack pattern, with diagonal cracks due to shear. The analysis of local responses highlighted that, for all the tests, flexural deformability contribution was predominant with respect to the shear one. However, shear contribution is generally not negligible and it increased if aspect ratio decreased, as expected.

Finally, a numerical modelling was carried out to reproduce the experimental envelopes of the tested specimens. A three-component model was adopted, in which the three mechanisms characterizing the lateral response of RC columns - flexure, shear and fixed-end-rotation are separately modeled. The monotonic numerical model was able to well reproduce the envelope of the experimental global response up to peak load condition for all the specimens. Also the experimental mean trends of the deformability contributions to the overall imposed drift were well reproduced by the numerical model for all the specimens.

Further developments of this work will deal with the numerical modelling of the post-peak behaviour especially for shear-critical piers, also on the basis of a wider number of properly collected experimental tests (as in [19]). 


\section{Acknowledgements}

This work was developed under the financial support of STRESS S.c.a.r.1. STRIT Project "PON Ricerca e Competitività 2007-2013" and "ReLUIS-DPC 2014-2018 PR 2- Linea Strutture in cemento armato", funded by the Italian Department of Civil Protection (DPC). These supports are gratefully acknowledged.

\section{REFERENCES}

[1] P.E. Pinto, A. Lupoi, P. Franchin, Valutazione e consolidamento sismico dei ponti esistenti. IUSS Press, 2009.

[2] M.J.N. Priestley, R. Park, Strength and ductility of concrete bridge columns under seismic loading. ACI Structural Journal, 84(1), 61-76, 1987.

[3] Y. Xiao, R. Ma, Seismic retrofit of RC circular columns using prefabricated composite jacketing. Journal of structural engineering, 123(10), 1357-1364, 1997.

[4] M.J.N. Priestley, F. Seible, Y. Xiao, Steel jacket retrofitting of reinforced concrete bridge columns for enhanced shear strength-Part 2: Test results and comparison with theory. Structural Journal; 91(5), 537-551, 1994.

[5] G. M. Calvi, A. Pavese, A. Rasulo, D. Bolognini, Experimental and numerical studies on the seismic response of RC hollow bridge piers. Bulletin of Earthquake Engineering; 3(3), 267-297, 2005.

[6] R. Delgado, P. Delgado, N. Vila Pouca, A. Arêde, P. Rocha, A. Costa, Shear effects on hollow section piers under seismic actions: experimental and numerical analysis. Bulletin of Earthquake Engineering, 7(2), 377-389, 2009.

[7] P. Delgado, Avaliação da Segurança Sísmica de Pontes. Doctoral dissertation, Ph. D., FEUP, 2009 (in Portuguese).

[8] P. Delgado, A. Monteiro, A. Arêde, N. V. Pouca, A. Costa, R. Delgado, Non Linear Shear Effects on the Cyclic Behaviour of RC Hollow Piers. Materials with Complex Behaviour II, 537-547, Springer Berlin Heidelberg, 2012.

[9] S. Popovics, A numerical approach to the complete stress strain curve for concrete. $\mathrm{Ce}$ ment and concrete research, 3(5), 583-599, 1973.

[10] M. Menegotto, P. E. Pinto, Method of analysis of cyclically loaded RC plane frames including changes in geometry and non-elastic behavior of elements under normal force and bending, Preliminary Report, IABSE, 13, 15-22, 1973.

[11] J. Krolicki, J. Maffei, G.M. Calvi, Shear strength of reinforced concrete walls subjected to cyclic loading. Journal of Earthquake Engineering, 15(S1), 30-71, 2011.

[12] R. Park, T. Paulay, Reinforced Concrete Structures, JohnWiley and Sons, Inc., New York, 1975.

[13] P.H. Miranda, G. M. Calvi, R. Pinho, M.J.N. Priestley, Displacement-based assessment of RC columns with limited shear resistance, ROSE Research Report No. 2005/04, IUSS Press, Pavia, Italy.

[14] M.J.N. Priestley, G.M. Calvi, M.J. Kowalsky, Displacement-based seismic design of structures. Pavia, Italy: IUSS press, 2007. 
[15] H. Sezen, E.J. Setzler. Reinforcement slip in reinforced concrete columns. ACI Structural Journal 105, 3, 2008.

[16] STRIT RT D.1.2 - part 1. Inventory e sviluppo database per la caratterizzazione della vulnerabilità delle infrastrutture viarie. STRIT Project "PON Ricerca e Competitività 2007-2013”, 2015.

[17] D. Biskinis, M.N. Fardis. Deformations at flexural yielding of members with continuous or lap-spliced bars. Structural concrete, 11(3), 127-138, 2010.

[18] F. McKenna, G.L. Fenves, M.H. Scott. Open system for earthquake engineering simulation, available at http://opensees.berkeley.edu, 2000.

[19] P. Cassese, M.T. De Risi, G.M. Verderame, Capacity models for shear-critical RC bridge piers with hollow cross-section, COMPDYN 2017 (paper ID 17545), 6th ECCOMAS Thematic Conference on Computational Methods in Structural Dynamics and Earthquake Engineering, M. Papadrakakis, M. Fragiadakis (eds.), Rhodes Island, Greece, 15-17 June 2017. 